\title{
Micro-Distribution of Anchovy Eggs and Larvae in Sagami Bay
}

\author{
Katsumi Matsushita, ${ }^{*}$ Makoto Shimizu* and Yukio Nose* \\ (Received August 5, 1981)
}

\begin{abstract}
In order to study the micro-distribution of anchovy Engraulis japonica (HouTTUYN) eggs and larvae, from the point of view of reproduction, consecutive net samplings were carried out by making distance of net towing as short as possible. The number of samplings was 20 times at each station. The distance of unit net towing was about $60 \mathrm{~m}$ at $2 \mathrm{knots}$ per minute. Total number of stations was 23.

A unique concentrated distribution of eggs and larvae was observed in the area of collection formed by the ocean current.

Anchovy eggs are distributed in a concentrated from like a patchiness on both large and small scale. Anchovy larvae were spread over wider area than the eggs, but they formed school on small scale

It is considered that the chance of encounter with the prey or predator are influenced by these concentrations of the eggs and larvae.
\end{abstract}

The eggs of marine fishes are almostly pelagic, and these egg number are numerous. Due to their spawning habitat, it is persumed that the pelagic eggs and larvae will have a special concentrative distribution. Depending on the nature of the structure of the distribution, the chance of encounter to forage will be change. ${ }^{12}$ These phenomena are very interesting for the study of population. In order to clarify these phenomena, it is necessary to survey the micro-distribution of eggs and larvae at first.

With regard to zoo and phyto plankton distribution, the micro-distribution has attracted the interests of many scientists since 1920's mainly on the problem of the riliability of net sampling. ${ }^{23}$ However, regarding to the pelagic eggs and larvae, apart from the study of their geographical distribution, little attention was made to study their micro-distribution. Some papers reported the physical transport and dispersion of sea water, in relation to the distribution of eggs and larvae, ${ }^{8,4}$ however, very rare are studies made on the microdistribution of pelagic eggs and larvae itself.

Furthermore, it is very important from the view point of the reliability of net sampling to survey the fluctuation of density in one net towing distance that is assumed to be habing a homogeneous nature. These results will be reported another paper.

The purpose of this paper is to make clear the micro-distribution of pelagic eggs and larvae by making distance of net sampling as short as towing possible.

\section{Method}

\section{Location}

This survey was carried out on KT-73-7 cruise of R. V. Tansei-maru, which belongs to Ocean Research Institute, Univ. of Tokyo, from 22 June 1973 to 28 June in Sagami Bay.

Three survey lines were made, Line 1: MisakiIto, Line 2: Shimoda-Ito, Line 3: Ito-Misaki (Fig. 1).

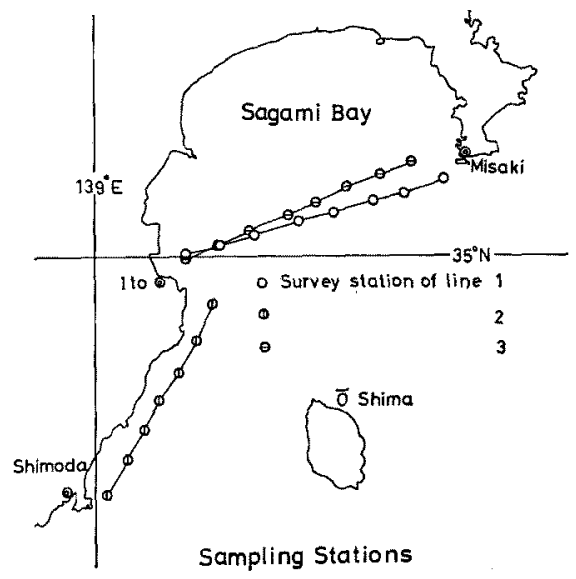

Fig. 1. Consecutive net sampling słations.

* Department of Fisheries, Faculty of Agriculture, University of Tokyo, 1-1, Yayoi-1, Bunkyo, Tokyo 113

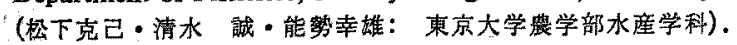


Table 1. Date and locality of sampling stations and lines. The time is starting time of consecutive sampling

\begin{tabular}{|c|c|c|c|c|c|c|}
\hline \multirow{2}{*}{ Location } & \multicolumn{2}{|c|}{$\begin{array}{c}\text { Line } 1 \\
\text { Misaki } \rightarrow \text { Ito }\end{array}$} & \multicolumn{2}{|c|}{$\begin{array}{l}\text { Line } 2 \\
\text { Shimoda }\end{array} \rightarrow$ Ito } & \multicolumn{2}{|c|}{$\begin{array}{c}\text { Line } 3 \\
\text { Ito } \rightarrow \text { Shimoda }\end{array}$} \\
\hline & $\begin{array}{r}35^{\circ}-06.7 \mathrm{~N} \\
139^{\circ}-35.3 \mathrm{E}\end{array}$ & $\begin{array}{r}35^{\circ}-00.4 \mathrm{~N} \\
139^{\circ}-09.3 \mathrm{E}\end{array}$ & $\begin{array}{r}34^{\circ}-40.1 \mathrm{~N} \\
139^{\circ}-01.5 \mathrm{E}\end{array}$ & $\begin{array}{r}34^{\circ}-55.6 \mathrm{~N} \\
139^{\circ}-11.8 \mathrm{E}\end{array}$ & $\begin{array}{r}34^{\circ}-59.6 \mathrm{~N} \\
139^{\circ}-08.3 \mathrm{E}\end{array}$ & $\begin{array}{r}35^{\circ}-07.7 \mathrm{~N} \\
139^{\circ}-31.7 \mathrm{E} \\
\end{array}$ \\
\hline Date & \multicolumn{2}{|c|}{ 22-June } & \multicolumn{2}{|c|}{ 26-June } & \multicolumn{2}{|c|}{ 28-June } \\
\hline Station No. & $\begin{array}{l}\text { Time } \\
\text { 13:01 }\end{array}$ & $\begin{array}{c}\text { Water temp. } \\
22.3^{\circ} \mathrm{C}\end{array}$ & $\begin{array}{l}\text { Time } \\
8: 46\end{array}$ & $\begin{array}{c}\text { Water temp. } \\
20.9^{\circ} \mathrm{C}\end{array}$ & $\begin{array}{l}\text { Time } \\
9: 19\end{array}$ & $\begin{array}{c}\text { Water temp. } \\
21.6^{\circ} \mathrm{C}\end{array}$ \\
\hline 2 & $13: 36$ & 22.5 & $9: 23$ & 21.3 & $9: 56$ & 21.6 \\
\hline 3 & $14: 16$ & 21.3 & $9: 59$ & 21.6 & $10: 30$ & 21.7 \\
\hline 4 & $15: 00$ & 21.4 & $10: 34$ & 21.9 & $11: 06$ & 21.8 \\
\hline 5 & $15: 40$ & 21.3 & $11: 09$ & 22.1 & $11: 41$ & 22.0 \\
\hline 6 & $16: 21$ & 21.7 & $11: 48$ & 22.2 & $12: 15$ & 21.8 \\
\hline 7 & $16: 59$ & 21.9 & $12: 30$ & 22.2 & $12: 50$ & 20.5 \\
\hline 8 & $17: 35$ & 21.8 & & & $13: 34$ & 20.9 \\
\hline
\end{tabular}

Survey stations were made on each survey line at equal distances, Line 1:8 stations, Line 2:7 stations, Line $3: 8$ stations. At each survey stations, consecutive net samplings were carried out 20 times (Table 1).

\section{Sampling Methods}

Samples were collected by surface horizontal haul with NORPAC net (mesh size $0.33 \mathrm{~mm}$ ), which were took away the side rope and weight, equipped with a flowmeter. Towing speed was 2 knots.

Two identical nets were used in alternately for every one minute. During one another net towing, it was carried out to read the rotation number of the flowmeter and to wash down the collected matters two times, as well as, to prepare for the next towing.

To avoid the influence on the mouth of the net with progressive waves of the ship, the nets were towed from the side boom.

One towing distance was $60 \mathrm{~m}$ at 2 knots. The survey was carried out for a distance of $1.2 \mathrm{~km}$ during consecutive net sampling of 20 times. During KT-73-7 cruise, the total net towing number were 460 times at Line 1-3.

The estimation of water volume filtered were carried out by the Rigo-sha flowmeter No. 292 and No. 304.

Surface water temperature was measured by thermometer and auto-thermometer. And, sufficiently attention was made to cleaning the nets in order to avoid clogging of net mesh.

\section{Measurement of the Samples}

Collected samples were immeadiately fixed on board with neutral formalin. After arrival at the laboratory, the settling volumes were measured and the eggs and larvae were identified and counted the number. And, the living body of the eggs and larvae were observed on board under the microscope for reference of identification.

The anchovy Engraulis japonica (HoutTuYN) eggs were classified as a: early stage, $b$ : middle stage, $c$ : late stage and larvae according to NAKAI et $\left.a .^{5}\right)$

\section{Results}

\section{Estimation of Water Volume Filtered}

According to the cariblation of the flowmeters, the water volume filtered were estimated as $0.0159 \mathrm{~m}^{3}$ (No. 292) and $0.0165 \mathrm{~m}^{3}$ (No. 304) per one rotation of flowmeter respectively. The means and standard deviations of water volume filtered about twenty net towings for each station are tabulated in Table 2 .

At some stations there were tendency to drop the water volume filtered for the net mesh clogging. It was conspicuous at St. 2 and 6 of Line 3.

Table 2. Means and standard deviations of water volume filtered $\left(\mathrm{m}^{3}\right)$ of twenty times at each station

\begin{tabular}{cccc}
\hline Station & Line 1 & Line 2 & Line 3 \\
\hline 1 & $7.67(0.41)$ & $9.44(1.48)$ & $8.27(0.55)$ \\
2 & $5.66(1.94)$ & $8.29(0.49)$ & $4.87(1.55)$ \\
3 & $5.84(1.10)$ & $9.60(0.41)$ & $6.10(1.06)$ \\
4 & $6.03(1.72)$ & $9.14(1.51)$ & $6.73(0.60)$ \\
5 & $6.63(1.10)$ & $8.59(0.63)$ & $5.37(0.77)$ \\
6 & $7.07(0.61)$ & $9.13(0.75)$ & $3.07(1.36)$ \\
7 & $7.47(0.80)$ & $9.37(0.79)$ & $6.46(0.51)$ \\
8 & $7.00(1.10)$ & & $6.79(0.92)$ \\
\hline
\end{tabular}


When the nets were washed especially more than two times for cleaning, the water volume filtered were increased at the next towing. Due to changes in the ship's speed, periodical fluctuations in water volume filtered also occured.

The water volume filtered of Line 2 were large and had little fluctuation. This was considered to be as the result of sparse density of organisms. But, in general, the rotation number of flowmeters were stabilized at each towing. It is considered that it is possible to estimate water volume filtered from rotation number of flowmeters.

\section{Distribution of Settling Volume}

The distribution of settling volume per $\mathrm{m}^{3}$ are shown in Fig. 2. For a period of these surveys, the noctiluca Noctiluca scintillans (MACARTNEY) has occured enormously at Sagami Bay and were ranked first place in settilng volume.

It is indicated that the settling volume had almostly little fluctuation among stations and there was not any tendency to concentrate at particular station as like the anchovy eggs. However, it was observed that there were considerable fluctuation in some stations and some species of plankton were aggregated at particular station and segment. These results will be reported in succession paper.

Comparing with the settling volume of Line 1 and 3 , the settling volume of Line 2 was sparse. It was considered that the water mass were different.

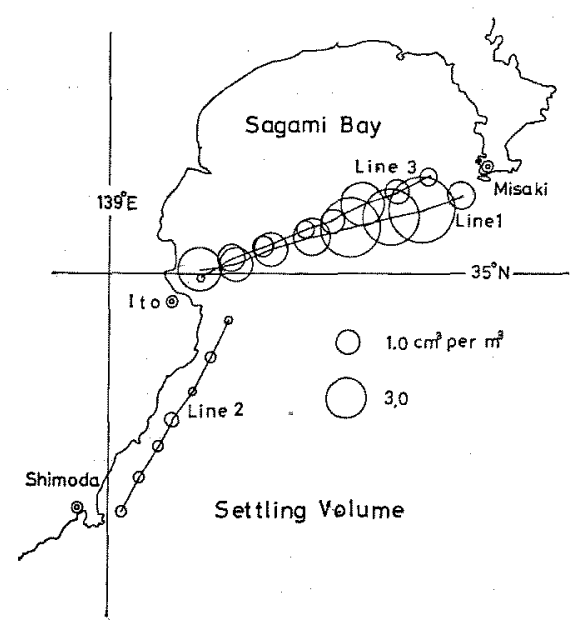

Fig. 2. Macro-distribution of settling volume per $\mathrm{m}^{3}$.

Macro-distribution of Anchovy Eggs and Larvae The average density of anchovy egg density for

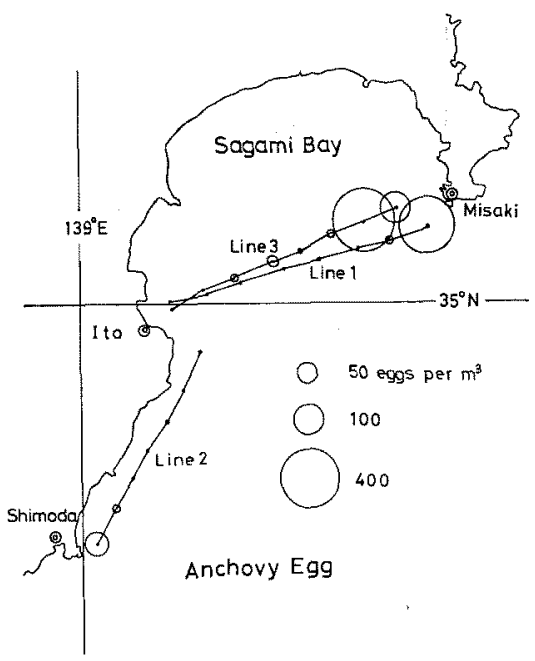

Fig. 3. Macro-distribution of total anchovy eggs per $\mathrm{m}^{3}$.

the twenty net towings at each station are shown in Fig. 3.

High density areas were formed at St. 1, 2 of Line 1, St. 1, 2 of Line 2 and St. 7, 8 of Line 3. From these informations it is clear that the main spawning area were off the coast of Misaki and Shimoda. Theses facts were agree to the Reports of Kanagawa Prefectual Fisheries Experimental Stations. ${ }^{\text {e) }}$

It is considered from the distribution of surface temperature that both areas were influenced by the southern water mass. There was an interval of 6 days between Line 1 and Line 3 investigations. During the 6 days, accompany the movement of the warmer area, the main spawning area of anchovy moved to west. However, the eggs of Line 3 were distributed in a wider area than in Line 1 and 2. However, since the anchovy eggs were collected at Line 1, 2 and 3 during the 6 days interval, it is assumed that the spawning group of anchovy have been staying continously at Sagami Bay.

In the next place, the distribution of anchovy larvae are shown in Fig. 4. The anchovy larvae were spread over all area of survey lines except Line 2. And then, the larvae were not collected at the St. 1 of Line 2 and the St. 7 of Line 3 where the eggs were enormously collected. However, the larvae were much collected at St. 3-8 of Line 1, St. 6 of Line 2 and St. 1 of Line 3 where the eggs were not collected.

The anchovy larvae were scaresly distributed 


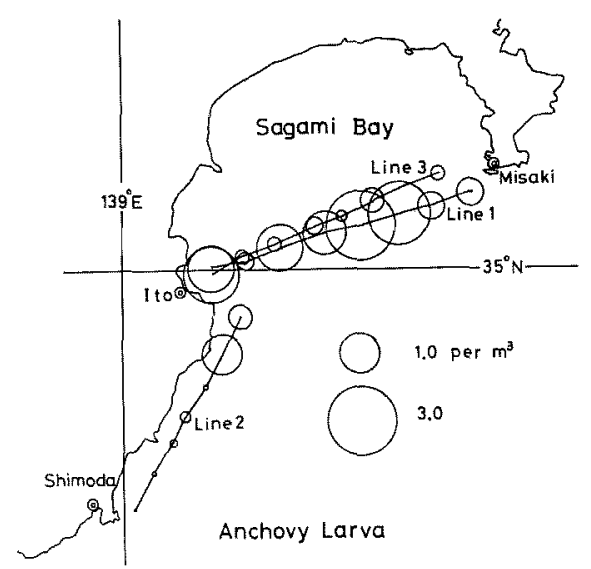

Fig. 4. Macro-distribution of anchovy larvae per $\mathrm{m}^{3}$.

off the west coast of Misaki and east coast of Shimoda where the eggs distributed densely. A weak inverse correlation between eggs and larvae was found.

The three staged eggs and larvae of anchovy are tabulated in Table 3. The table indicates that there was a tendency of the number of egg to decrease as the egg development.

The anchovy eggs were collected only at St. 1, 2 as regards to Line 1. But, as for Line 2, a few eggs were also collected at another stations except at St. 1, 2 where eggs were abundantly collected. As for Line 3, there were two peaks of the distribution at St. 3, 4 and St. 6, 7, 8. At St. 3, 4 the late stage eggs were mainly collected. While the early stage eggs were mainly collected at St. 7, 8 with few late stage eggs.
Generally, from the observations that the height of peak of the early stage eggs were higher than the peak of the middle and late stage eggs, the early stage eggs were considered to be more concentrated than the other stage eggs. But; since all stage eggs were collected mostly at same stations, there was not tendency that the later stage eggs were distributed in wider area than earlier stage eggs.

\section{Micro-Distribution of Anchovy Eggs and Larvae}

The micro-distribution of three stage eggs and larvae of anchovy for each station are shown in Fig. 5. The distribution of the anchovy eggs were not random but were found to be concentrated at a particular area, probably at the spawning area, and generally decreased and spread around the center of the dense area. The eggs were distributed continuously from St. 1 to St. 2 of Line 1 and 2 respectively. And then, the distribution terminated at St. 2 of Line 1 and 2. The distance of station was $4.3-4.8 \mathrm{~km}$.

The peak and fluctuation of the early stage eggs were simultaneous with the peak and fluctuation of the middle stage eggs at St. 1 of Line 1. However this pehnomenon was due to the individual difference in development speed, it is considered that the spawning group were same.

The existence of a specialy concentrated distribution were observed at segment No. 12 and 18 at St. 1 of Line 2. The values of these two peaks reached about 150 times and about 98 times as many as level of the background. And the length of the peaks were $180-240 \mathrm{~m}$ respectively. The distance between these two peaks was $300-420 \mathrm{~m}$. The peaks of early stage eggs coincide at the same

Table 3. Total number of Anchovy eggs and larvae were caught at each station

\begin{tabular}{|c|c|c|c|c|c|c|c|c|c|c|}
\hline \multirow{2}{*}{ Line No. } & \multirow{2}{*}{\multicolumn{2}{|c|}{ Stage }} & \multicolumn{8}{|c|}{ Station No. } \\
\hline & & & 1 & 2 & 3 & 4 & 5 & 6 & 7 & 8 \\
\hline \multirow{4}{*}{1} & Egg & a & 28271 & 1075 & 0 & 0 & 0 & 0 & 0 & 0 \\
\hline & & $b$ & 18987 & 1 & 0 & 0 & 0 & 0 & 0 & 0 \\
\hline & & c & 580 & 4 & 0 & 0 & 0 & 0 & 0 & 0 \\
\hline & Lary & & 76 & 45 & 288 & 363 & 145 & 201 & 24 & 202 \\
\hline \multirow{4}{*}{2} & Egg & a & 9313 & 80 & 0 & 3 & 2 & 0 & 1 & \\
\hline & & b & 0 & 0 & 0 & 0 & 2 & 0 & 0 & \\
\hline & & c & 1572 & 62 & 1 & 1 & 0 & 0 & 0 & \\
\hline & Larv & & 0 & 2 & 4 & 10 & 2 & 179 & 69 & \\
\hline \multirow{4}{*}{3} & Egg & $\mathbf{a}$ & 0 & 1 & 29 & 146 & 22 & 148 & 47804 & 13712 \\
\hline & & $b$ & 0 & 1 & 0 & 1 & 0 & 100 & 0 & 670 \\
\hline & & $c$ & 0 & 0 & 893 & 330 & 4 & 40 & 7913 & 1137 \\
\hline & Larv & & 324 & 10 & 17 & 22 & 7 & 21 & 0 & 14 \\
\hline
\end{tabular}




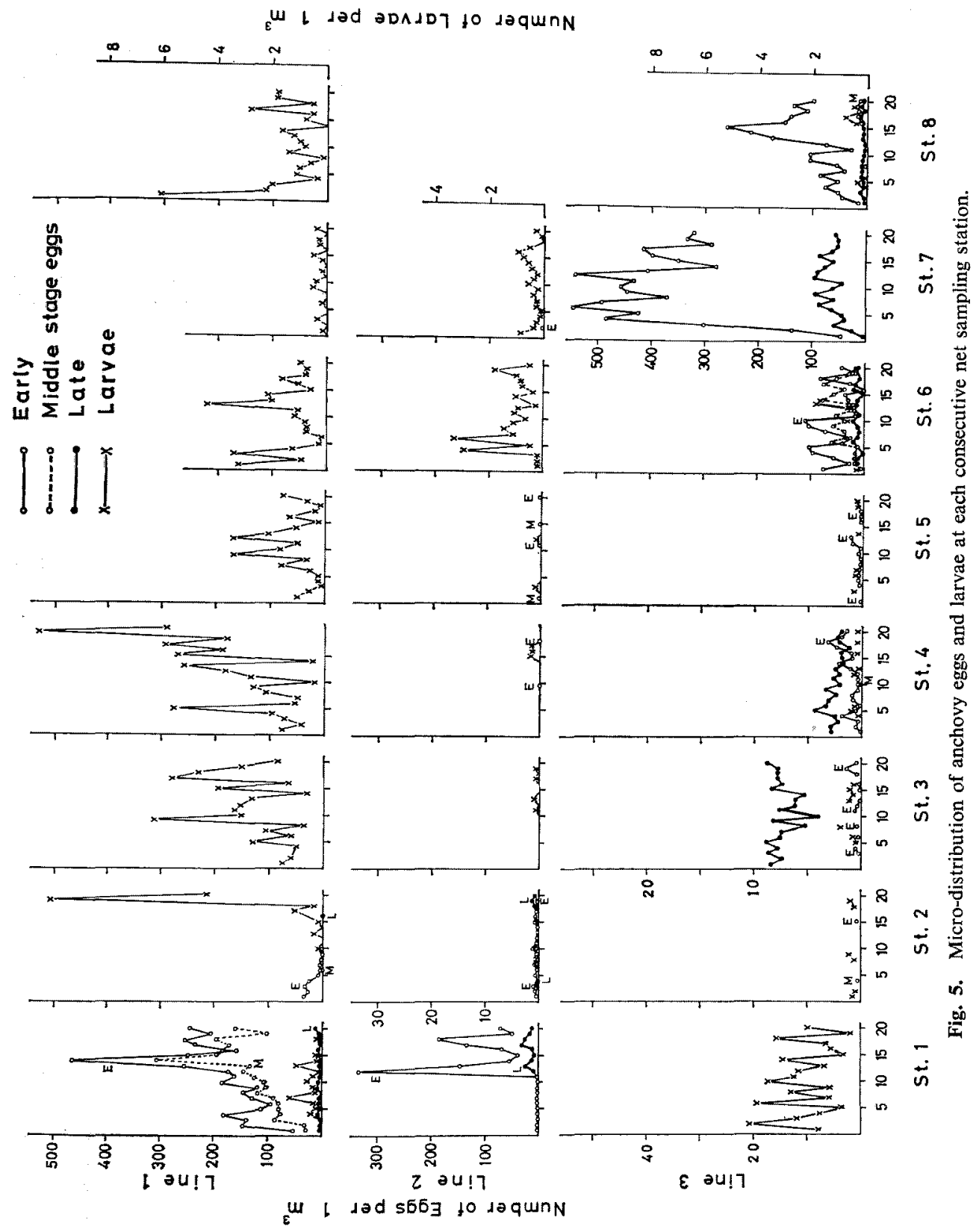


segment number with peak of the late stage eggs, the settling volume, copepoda and noctiluca. Floating matters and seaweeds were observed around at segment number 12 and 18 when the nets were towing.

There was a unique shape at the peak of segment No. 12. The left side of this peak sharply increased from the background, mostly with 0 values, within the distance of $60 \mathrm{~m}$. However, the right side of this peak had a gentle slope. The change in temperature decreased at first $0.3^{\circ} \mathrm{C}$ from $20.9^{\circ} \mathrm{C}$, however, raised rapidly to $21.2^{\circ} \mathrm{C}$ at segment No. 14 , then, decreased again to $21.0^{\circ} \mathrm{C}$. The water temperature fuctuation seemed to have a similar tendency to the fluctuation of the anchovy eggs.

For the larvae it seemed that both the large and small groups were dispersed at random. There was a conspicuous peak at segment No. 19 at St. 2 of Line 1. Many peaks were also observed at the other stations. Compared to those of the eggs peaks, these peaks were sharp and their width were smaller.

\section{Distribution Pattern}

For the purpose of comparison with theoretical type of the distribution patterns of the early, middle, late stage eggs and larvae of anchovy and the settling volume, the data of these one dimentional results were applied as a matter of convenience to the equation of $I_{\delta}$ index. ${ }^{7}$.

The results of the twenty towings were subdivided into a series of quadrats of $1 / 2,1 / 4,1 / 5$, $1 / 10$ and $1 / 20$ of total distance, and then, the $I_{\delta}^{\prime}$ index were calculated. The results are shown in Table 4.

The settling volume mostly had random distribution, while the anchovy eggs mainly had contagious distribution with small clump. This indicates that the anchovy eggs had a tendency to be concentrate in their distribution.

Table 4. Comparison of $I_{\delta^{\prime}}$ values with each stage egg, larva abd settling volume

\begin{tabular}{|c|c|c|c|c|c|c|}
\hline \multirow{2}{*}{\multicolumn{2}{|c|}{ Station }} & \multicolumn{4}{|c|}{ Englaulis japonica } & \multirow{3}{*}{ Settling volume } \\
\hline & & \multirow[b]{2}{*}{ Early stage } & \multicolumn{2}{|c|}{ Egg } & \multirow{2}{*}{ Larva } & \\
\hline & No. & & Middle stage & Late stage & & \\
\hline \multirow[t]{8}{*}{ Line 1} & 1 & SC-R & SC-R & $\mathbf{R}$ & SC-R & $\mathbf{R}$ \\
\hline & 2 & SC-R & - & - & SC-R & SC-R \\
\hline & 3 & - & - & - & SC-R & SC-R \\
\hline & 4 & - & - & - & SC-R & $\mathbf{R}$ \\
\hline & $s$ & - & - & - & SC-R & $\mathbf{R}$ \\
\hline & 6 & - & - & - & SC-R & $\mathrm{R}$ \\
\hline & 7 & - & - & - & SC-R & $\mathbf{R}$ \\
\hline & 8 & - & - & - & SC-R & $\mathbf{R}$ \\
\hline \multirow[t]{7}{*}{ Line 2} & 1 & SC-R & - & SC-R & - & $\mathbf{R}$ \\
\hline & 2 & SC-R & - & SC-R & - & $\mathbf{R}$ \\
\hline & 3 & - & - & - & - & $\mathbf{R}$ \\
\hline & 4 & - & - & - & SC-R & SC-R \\
\hline & 5 & - & - & - & - & U \\
\hline & 6 & 一 & - & - & SC-R & $\mathrm{U}$ \\
\hline & 7 & - & - & - & SC-R & $\mathbf{U}$ \\
\hline \multirow[t]{8}{*}{ Line 3} & 1 & - & - & - & SC-R & $\mathbf{U}$ \\
\hline & 2 & 一 & - & - & SC-R & $\mathbf{R}$ \\
\hline & 3 & $\mathbf{U}$ & - & $\mathbf{R}$ & SC-R & $\mathbf{R}$ \\
\hline & 4. & $\mathrm{LC}-\mathrm{U}$ & - & $\mathrm{U}$ & SC-R & $\mathbf{R}$ \\
\hline & 5 & SC-R & - & - & - & $\mathbf{R}$ \\
\hline & 6 & R & $\mathbf{U}$ & U & SC-R & $\mathbf{R}$ \\
\hline & 7 & SC-R & - & $\mathbf{R}$ & - & $\mathbf{R}$ \\
\hline & 8 & SC-R & $\mathrm{SC}-\mathbf{U}$ & $\mathbf{R}$ & SC-R & $\mathbf{R}$ \\
\hline
\end{tabular}

\footnotetext{
SC-R; Contagious distribution with small clump and Intra-clump distribution is at random

SC-U; Contagious distribution with small clump and Intra-clump distribution is uniform.

LC-U; Contagious distribution with large clump and Intra-clump distribution is uniform.

R; Random distribution.

U; Uniform distribution.

-; The data is insufficient.
} 
Table 5. Comparison of means and standard deviations of the relative average variation rates of 23 stations

\begin{tabular}{llcc}
\hline & \multicolumn{2}{c}{ Relative average variation rate } \\
\cline { 3 - 4 } & & Mean & $\begin{array}{c}\text { Standard } \\
\text { deviation }\end{array}$ \\
\hline Engraulis & Early & 0.324 & 0.222 \\
japonica & Middle & 0.412 & 0.272 \\
& Late & 0.305 & 0.243 \\
& Larva & 0.367 & 0.150 \\
\hline Settling volume & 0.114 & 0.064 \\
Noctiluca & 0.168 & 0.096 \\
Copepoda & 0.145 & 0.078 \\
\hline
\end{tabular}

\section{Relative Average Variation Rate}

The relative average variation rates (RAVR) $\left.{ }^{8}\right)$ were calculated for the early, middle, late stage eggs and larvae of anchovy, noctiluca, copepoda and settling volume for each station.

The means and standard deviations of RAVR of 23 stations are tabulated in Table 5. The means of RAVR of the eggs and larvae have a tendency to be larger than the RAVR of the settling volume and the other planktons.

The standard deviations of RAVR of the anchovy eggs had a tendency to be larger than those of the larvae, the settling volume and the other planktons.

It is indicated that the fluctuation of density of the anchovy eggs in one station and between each station was larger than the others. On the contrary, the values of the standard deviations of RAVR of the others were small. It is evidient that the anchovy larvae were aggregated within stations. However, the variation of the distribution pattern between each station was little, since the anchovy larvae were distributed entirely in the survey lines.

\section{Discussion}

Concerning to the variation of population size, the variation between strength of year class have a stronger effect than the variation in progressive decrease of the catch or the natural mortality in one year class. It is considered that the main cause of the fluctuation of population is the level of recruitment which should determine the initial value of the year class. ${ }^{\natural)}$ That is to say, whether success or failure of their reproduction is an important point.

Furthermore, the fluctuation in reproduction depends on the mortality rate of larvae. Since the number of the eggs spawned are large and most of them die, a little decrease in mortality rate can increase survival rate by several times.

It is well known that most of larvae hatched have no ability to swim. If the density of their food around them is not more than a certain level, they can not alive. ${ }^{10}$ )

Generally, the density of the food in the coean is rare. It is considered that the micro-distribution of the larvae and their food substance have an important role in the mechanism of survival. ${ }^{11}$ )

Investigations of zoo and phyto plankton, using the Hardy Recorder ${ }^{12-18)}$ or pump sampler ${ }^{16,17)}$ have been carried out. MILLER ${ }^{18}$ / has investigated the larvae of some species using a unique net sampler with a distance of $240 \mathrm{~m}$.

Depending on these investigations, it is pointed out that both zoo and phyto plankton and larvae have a structure of patchiness.

Large mass of pelagic eggs were founded in the area of Misaki and Shimoda. Anchovy eggs formed wide distribution with a low density area where the density gradually decreased around the highest density center. This result agreed with the structure as reported by ANRAKU. ${ }^{16)}$

The peak of the distribution of the eggs were observed at the edge of the peak area of temperature, the peak of the distribution of eggs of Line 3 have moved to west coinciding with the water mass movement that were judged from the distribution of temperature.

It suggests that the structure of ocean current has an important role with regard to deciding the structure of the distribution of the anchovy eggs.

During this survey, since the range of temperature was $20-25^{\circ} \mathrm{C}$, the hatched time of the egg of anchovy must have been $20-30$ hours. ${ }^{5,20}$ ) Therefore, it is considered that the early and late stage eggs which were collected at the same time were respectively originated from one day different spawning time.

It was rare to be catched only one stage eggs, the extent of the distribution of each stage eggs were mostly the same.

It is considered that the late stage eggs of St. 3, 4 of Line 3 were transported during one day, since these station's depth is the most deepest area in Sagami Bay and the spawning ground of anchovy is not apart 10 miles from $200 \mathrm{~m}$ isodepth. ${ }^{20)}$

It is cleared that there is large fluctuation of the density at each segment in the distance of $1.2 \mathrm{~km}$, this distance is normally one towing length. In 
this distance the distribution of the eggs and larvae is not at random and have a different nature. Therefore, it is needed a careful consideration to represent the field density with the data based on one net towing.

As for the cause of these fluctuation, with regard to zoo and phyto plankton, two types have been suggested that one is circumstantial influence ${ }^{15)}$ and the other is organisms's ability of aggregation and multiplication. ${ }^{21)}$ As for the pelagic eggs, two causes were observed in this survey. One is concentrating action of ocean current, and the other is a mass which are originated from the spawning group. That is to say, the high density areas of St. 1 of Line 2 are formed only a distance of $60 \mathrm{~m}$. Since the peak of density of the other many species coincided with at the particular segment number and the floating matters and seaweeds were observed at the same segment number, it is cosidered that this high density areas were formed by the concentrating action of the ocean current.

And then, considering from the shape of the peak, there are two lines of concentration at the segment No. 12 and 18, and the pelagic eggs were concentrated at the segment No. 12 from right side and at the segment No. 18 from both side respectively.

That is to say, the west wind, force 5, has been browing at the survey area from the previous night, if the Langmur circulation ${ }^{22)}$ were formed by the wind, it is considered that the streaks have been formed rectangular against the ship direction of Line 2.

The RAVR of the anchovy eggs and larvae were higher than the settling volume, noctiluca and copepoda. However, concerning to larvae, the variation among the each station were small comparing with the eggs, and the distribution pattern $\left(\mathrm{I}_{\delta}^{\prime}\right.$ index) of the larvae was almostly the contagious distribution with small clump. This indicated that the anchovy larvae were formed a small school, but the school spread over at surface in survey lines vaster than the eggs.

\section{Acknowledgement}

The authors express their sincere thanks to officers and crew of R. V. Tansei-maru for their works and to members of Ocean Reserch Institute for their help when the survey were carried out.

\section{References}

1) B. C. IVElev: Dietetic Ecology of Fish, second edition, Tatara Shobo, yonago, 1970.

2) W. A. Herdman: Proc. Trans. Liverpool Bio. Soc., 35, 161-174 (1921).

3) K. Takizawa and W. Sakamoto: Bull. Japan. Soc.Sci. Fish., 46, 157-165 (1980).

4) H. Nakata and T. Hirano: Bull. Japan. Soci. Fish. Oceanog., 32, 1-14 (1978).

5) J. NAkai, S. HatTori and T. Watabe: Achivements of Tokai Regional Fisheries Research Institute, No. 338 (1960)

6) I. MrYa: Report of Kanagawa Prefectual Fisheries Experimental Stations, No. 259, 1-61 (1978).

7) M. Moroshrta: Mem. Fac. Sci. Kyushu Univ., Ser, E (Biol), 2, 215-235 (1935).

8) K. Suzuki: Japan. J. Ecol., 10, 168-171 (1960).

9) J. G. ShePherd and D. H. Cushing: J. Cos. int. Expolr, Mer, 39, 160-167 (1980).

10) C. P. O'ConNel and L. P. RAYMond: J. Exp. Mar. Biol. Ecol., 5, 187-197 (1970).

11) J. R. Hunter and G. L. Thomas: The early life histry of fish, springerverlag, 559-574 (1974).

12) A. C. HaRdy: Discovery Reports, 11, 1-456 (1935).

13) A. C. HaRdY: Discovery Reports, 11, $511-538$ (1936).

14) P. H. Wrebe: Limnol. Oceanog., 13, 205-217 (1968).

15) R. M. Cassie: New Zealand J. Sci., 2, 339-365 (1959a).

16) M. AnRaku: Bull. Plankton Soc. Japan. 22, 17-26 (1975)

17) A. Kuwahara, T. Abe, M. Shmono, M. KaSHIwaI and M. SHInoda: J. Oceanog. Sci. Japan, 29, 106-112 (1974).

18) J. M. MrLleR: Limnol. Oceanog., 18: 175-178 (1973).

19) K. Uchida, S. Imai, S. Mrto, S. Fujita, M. Ueno, Y. Shouma, T. Senta, M. Tahuku, and $Y$. Dotsu: Studies on the eggs, larvae and juvenile of japanese fishes, Kyushu Univ., Fac. Dep., Second Lab., Fish. Biol., Ser. 1. pp. 89 (1958).

20) K. Kondo: Bull. Tokai Regional Fish. Res. Lab., 47, 51-84 (1966).

21) M. BernhaRd and L. RAMPI: Botan. Gothoburgensia, 3, 13-24 (1965).

22) I. LANGMur: Science, 87, 119-123 (1938). 